part of June, 1892 ; and at the request of her local adviser she consulted Dr. Gowers. As I have not the privilege of a personal acquaintance with Dr. Gowers, I did not like to write to him; but his opinion, so far as I could understand it when filtered through a lay medium, was very unfavourable in every way. From time to time I heard through the mother of the patient's downward course ; of the little importance of the arthritic troubles as compared with the vital complications of the higher nerve centres; and of the gradual death, which came from paralysis of respiratory nerves in June, 1893.

Reviewing briefly the salient points of these three cases, there are special facts beyond all debate. (1) The rheumatoid phenomena were unquestionable. (2) In the first patient the bulbar disturbance began quite early in the medical history. Candidly confessing as I do that I did not rightly interpret this disturbance, and undervalued its meaning, it may be recorded as a happy coincidence that a firm and persevering treatment, carried on during several years, succeeded in quelling the rebellion of the nerves and nerve centres all along the line. (3) Bulbar symptoms, after they have passed the stage of inco-ordination and are accompanied by clear atrophy, are practically incurable. In the second case they came and developed under my own eyes with startling rapidity, and all the time the arthritis receded and almost went away. (4) Bulbar symptoms and rheumatoid arthritis, with its characteristic atrophy, may develop together, as in my third case. From the very commencement of my patient's illness both groups of lesions went on almost pari passu, and even at the last it could not be said that the arthritis had at all gone into the background.

I may be allowed to quote just one more example of an abstruse subject by showing that a paresis of muscle, not reaching the debility of atrophy, may travel downwards in the spinal column instead of upwards. Thus, a lady of middle age, living in Scotland, was sent to me by Dr. Byrom Bramwell in the autumn of 1891 . The rheumatoidal symptoms were decided but not severe, and she steadily improved in every way. Her third visit to Bath, in the spring of 1893, was ended by"a sort of medical tragedy; for a weakness came like a cloud over the lower limbs, so that she could scarcely move, and could not walk at all. I' Ihere was little wasting and no increase in the arthritis. I sent her home as soon as possible, but the last news of her (a few weeks ago) was not at all encouraging. Once more: I have watched for ten or eleven years a case of scleroderma of the leg complicated with rheumatoid trouble in the neighbouring knee-joint. I did not know or even suspect that there was any pathological connection between the two until I came across a pregnant and suggestive paragraph in Dr. Jamieson's book on Diseases of the skin, in which he points out that scleroderma and rheumatoid arthritis may occur in the same person because both are essentially atrophic processes.

If I am plainly asked what proof have I given of the proposition with which I started, where are my post-mortem examinations, and my microscopic specimens, I must drily answer that people who have rheumatoid arthritis do not commonly die in Bath. Either we greatly relieve them as soon as we can, or we send them away as incurable. To quote from a quaint seventeenth-century writer on the Bath waters, "We prefer that some other bell shall toll for them rather than our own big bell of SS. Peter and Paul." My simple aim has been to scatter a few thoughts worth thinking about; and on a future occasion I may be allowed to offer some sug gestions for the preventive treatment of rheumatoid atrophy

\section{A DIASTOLIC BRUIT AT THE APEX IN THE HEART DISEASE OF CHILDREN.}

\section{Bx THEODORE FISHER, M.D.LoND.,}

Registrar to the Bristol General Hospital.

Dr. Sansom, in his recent work upon the diseases of the heart, states that the only bruit that can be mistaken for the presystolic bruit indicating mitral stenosis is a diastolic bruit due to aortic regurgitation heard at the apex. There is another sound that at least may lead observers of limited experience to an incorrect conclusion. That is a diastolic or sometimes presystolic sound not infrequently heard at the apex in association with a dilated heart. Dr. Donkin $^{1}$ has noticed a well-marked example, and after speaking of diastolic sounds at the apex says: "And lastly I would record a remarkable case in a child of 8 , where a loud and long diastolic murmur as well as a systolic was always heard at the apex, but the necropsy showed a mitral orifice of fully 3 inches round and no lesion other than a few small granulations on the auricular surface. Such a diastolic murmur, as is well known, is usually associated with marked mitral stenosis."

Through the kindness of Dr. Lauriston Shaw I have recently examined the post-mortem records of cases of adherent pericardium in children who died in Guy's Hospital during the space of seven years. In all cases (13 in number) presumably due to rheumatism, that is to eay in all cases not secondary to phthisis, left-sided pleurisy or some other local cause, the heart was considerably hypertrophied and dilated. In the clinical reports of these 13 cases it was found that in 5 instances a diastolic or a presystolic bruit had been present at the apex, yet the necropsy showed that the mitral orifice was dilated and that the aortic valves were not thickened.

The following are brief notes:

CASE I.-Girl, aged 12, admitted under Dr. Goodhart, February, 1886. Loud systolic bruit at apex, alternating with a rumbling sound.

Post mortem, heart weight 23 ounces; mitral orifice dilated, the mitral valves slightly thickened. The aortic valves competent, but showed minute granulations along their lunulæ.

CASE II.-Boy, aged 10, under Dr. Frederick Taylor, January, 1887. A loud systolic bruit at apex, and something heard after it, "probably a diastolic bruit." A thrill was also present, but whether systolic or presystolic was considered doubtful.

Post mortem coart weight 10 ounces; both the aortic and mitral valves were quite healthy, except that they were fringed with small bead-like granulations.

CASE III.-Boy, aged 13, admitted under Dr. Pye-Smith, November, 1890. Systolic bruit, audible at impulse, and rumbling sound presystolic in time.

Pos: mortem, heart weight 22 ounces; mitral orifice dilated, valves not Post mortem, heart weight 22 ounces
thickened, aortic valves also healthy.

CASE IV.-Boy, valves also healthy. 12 admitted under Dr. Hale White, January, 1890. Marked systolic thrill, and a systolic bruit audible at impulse. Three Marked systolic thrill, and a systolic bruit audible at i.

Post mortem heart weight 13 ounces; mitral orifice enlarged, valves not Post mortem, heart weight 13 ounce
thickened; other valves unaffected.

thickened; other valves unaffected. CASE v.-Girl, aged 11, admitted under Dr. Goodhart, February, 1892.
A slight systolic thrill, mitral systolic murmur, and a diastolic murmurat apex

Post mortem, heart weight 17 ounces; mitral valves thickened, the orifice dilated, aortic valves not thickened.

Here we have five cases in which a presystolic or a diastolic sound was associated, not with mitral stenosis, but with combined dilatation of the left ventricle and of the mitral orifice. It may be said by some that, although there was no actual mitral constriction, the relative size of the mitral orifice was probably small compared with that of the cavity of the ventricle. Whether such is the explanation of the sound ornot, it does not alter the fact that the bruit did not point to. stenosis of the mitral valves. That even relative contraction of the mitral orifice need not be present is shown by a case that recently died under the care of Dr. Harrison in the Bristol General Hospital.

In a boy, aged 13, admitted for cardiac disease, a systolic murmur at the apex was preceded by a rumble. After death the pericardium was found to be universally adherent, the heart greatly enlarged, and the mitral orifice sufficiently wide to admit five fingers. I have seen one other case in which the necropsy showed that a presystolic rumble was unassociated with mitral constriction. It was in a boy, aged 8, under the care of Dr. Wheaton in the Royal Hospital for Children and Women, Waterloo Bridge Road, S.E. In addition to a systolic bruit, a long low-pitched rumble occupied the diastolic interval, and was apparently also heard during the systole. At the postmortem examination the heart was found to be enlarged, weighing 10 ounces. The mitral valves were thickened and contracted, but the mitral orifice measured $3 \frac{1}{4}$ inches. The aortic valves were thickened but not incompetent. In connection with this case it may be mentioned that, as in three of the cases that occurred in Guy's Hospital, a systolic thrill was present. This thrill, at least to a careless or inexperienced observer, might be an additional source of error and be taken to confirm the idea that the presystolic sound pointed to mitral stenosis. The thrill is, however, 
systolic, not presystolic, but if the heart were beating rapidly the exact time of its occurrence would not always be easy to ascertain.

Since the above was written Dr. Sturges has mentioned, in his lectures upon Heart Inflammation in Children, five instances in which a thrill and presystolic murmur were noted during life, while mitral stenosis was found on postmortem examination to be absent. It is noteworthy that Dr. Sturges uses the words "thrill and presystolic murmur," from which we may infer that the thrill was not thought to be presystolic.

Dr. Cheadle has noticed the frequency of a diastolic sound in the early endocarditis of children, and states that, although it may disappear, it generally develops into the presystolic bruit of mitral stenosis. ${ }^{2}$

Possibly the diastolic sound that disappears, although indistinguishable at this stage from that of early mitral stenosis, may indicate temporary dilatation of the heart. The sound heard in the diastolic interval in association with a dilated heart may be either a sound separated by an interval both from the second or the first sound, or it may be a lowpitched presystolic rumble. As is well known, the presystolic bruit of mitral stenosis may often be replaced by a diastolic sound. The soft presystolic rumble of a dilated heart may also alternate with a diastolic sound.

The presystolic rumble of a dilated heart is, however, probably too low pitched to lead to much difficulty in diagnosis, and, when changed for a diastolic sound, the accentuation and rhythm may be that of the bruit de galop. There is, however, a diastolic murmur heard in the dilated heart of children which is presumably due to that dilatation, and is indistinguishable from the diastolic sound of mitral stenosis. It may be best heard at the impulse or just outside it, or over the right ventricle in the third and fourth or fourth and fifth intercostal spaces. In one position it is probably produced in the left ventricle, in the other in the right. In the same heart it may sometimes be best heard in one position, sometimes in the other, and then probably points to general dilatation.

Whether such a murmur indicates mitral stenosis or dilatation of the heart is of some importance. Adherent pericardium is the most common cause of a dilated heart in childhood, and death from such a cause is far more common than from mitral stenosis. Thus the post-mortem reports at Guy's for seven years showed that there were only 3 deaths from mitral stenosis of the age of 15 years and under, while there were 13 deaths from cardiac disease with adherent pericardium, in which valvular disease was either absent, or there was merely slight thiekening of the mitral valves. Apparently very few children with adherent pericardium survive the age of fifteen, while mitral stenosis is not uncommon in young adults. This suggests that the immediate prognosis is considerably worse in the former affection. A diastolic sound, therefore, indicating persisting dilatation of the heart, is probably of far more serious import than one pointing to mitral stenosis.

\section{A CASE OF SENSORY APHASIA, ACCOMPANIED BY WORD DEAFNESS, WORD BLINDNESS, AND AGRAPHIA.}

By HARDING H. TOMKINS, M.R.C.S., ETC.,

Kate Assistant Medical Officer, Gloucester County Asylum ; and Clinical Assistant, West Riding Asylum, Wakefield, Yorks.

I AMr indebted to my brother, Mr. Alfred J. Tomkins, of Brighton, for many notes and permission to publish the following case :

Past History.-A. N., aged 40, tailor, had had a slight tendency to hæmophilia from youth. In November, 1890, and again in February, 1892, he had slight hemoptysis, probably from a varicose vein, visible in the pharynx. In April, 1892, he had slight hæmorrhage from urethra after coition (seldom practised for some time previously). He had been something of an athlete and boxer, had lived freely, and still drank beer freely and smoked perliaps to excess. There was no history of syphilis. He had suffered much mental anxiety and business worry due to the recent death of his brother. (head of firm), and consequent frequent journeys to London by early train, great activity while there, often without food, resulting in exhaustion on returning to Brighton in the evening. general health was good, but he was somewhat obese and plethoric in

${ }^{2}$ Keatings Enx yclop e $i$ ia of Diseases of Children, vol. ii, part ii, p. 777. appearance. The heart was hypertrophied, and the second sound accentuated and slapping in character. The pulse was tense, rapid, and powerful.

Attack.-Having felt specially well and bright that day (July 24th, 1892), he was conversing quietly about noon when he suddenly became unable to recollect words. Feeling bewildered and somewhat faint he sat down for a while, but getting worse, and becoming excited in consequence of his inability to make those around him comprehend his meaning, a friend took him nearly lome. He then walked on to my brother's house. He next went home, a few hundred yards, and lay down. About an hour after he was visited by my brother, who found that a patch of subconjunctival hæmorrhage had developed at the outer canthus of the left eye. The patient was entirely unable to converse, using wrong words and frequently only syllabic sounds, not real words; he had some pain in the left temple. Deeming it inadvisable to excite him, no further examination was made. Between 1 P.M. and 11.30 P.M. he vomited twice, had free evacuation of the bowels, and passed urine copiously. He was given bromide of potassium and chloral hydrate, and had a fairly good night. On July 25 th he was mostly drowsy, at times excitable and irritable, and complained of pain in the left occipital region. Urine, $\frac{1}{4}$ albumen, clear, no blood.

On July 26 th he was quieter. Bowels and urine as before.

On July 28 th he was very restless, and thought himself well enough to go to work; however, he could not understand anything said to him without pantomime (for example, told to put out his tongue he offered his hand, though the pulse had just been taken); he could not whistle to accompaniment (a favourite pastime); could not write to dictation, but letters of which were intelligible, but which were simply jargon in them-
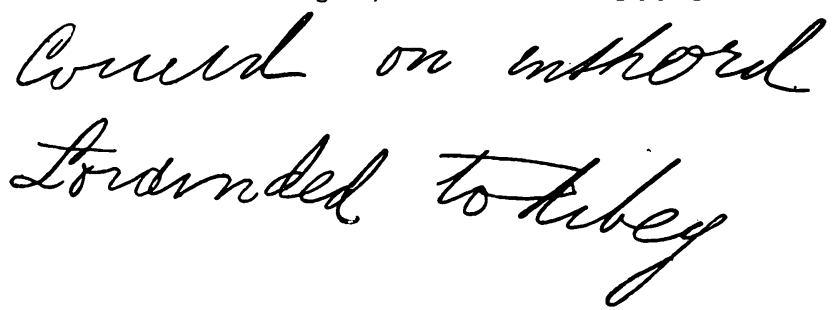

Fig. 1.

selves, as is shown in the reproduction (Fig. 1); some time soon after this he wrote his name fairly well when practising alone. He could not read at all, but used such sounds as "todibeg," "coweid," "wiz," and "schloth"; he could not name his children except the eldest, and could not make himself understood without a good deal of pantomime, as he was unable to compose a sentence, and generally used unintelligible sounds for words. He was ordered liq. hydrarg. et sodii iodidi.

From this time onward the albumen decreased to practically nil, with an occasional trace, as on August 17th.

By July 31st speech was improving slowly, and urine decidedly less albuminous.

On August 4th, happening to visit my brother, we went to see him, and by ophthalmoscopic examination I found both dises slightly too red, vessels distended and edges of discs slightly but distinctly blurred. No recent or old hærm.orrhage or other abnormality; as far as could be ascertained no defect of vision and no hemianopsia; could certainiy see small type, though unable to read.

On August 10th, word deafness was less marked, but he did not always interpret well. Word blindness was present. He could not name a child, nor recognise a picture of a fowl or donkey, but called the picture of a little girl "a kid."

On August 11th he could copy the figures in items of a bill for a suit of clothes, and add up correctly. The biniodide was stopped and he was given iodide of potassium gr. $\mathrm{v}$.

On August 17 th he talked better, complained of bloodshot eye. Urine which had become normal, now contained albumen; pulse hard, 100

On September 1st he went to Barcombe for change, as it worried him to try and talk to friends. Previously to this he had regained the power of whistling, and also volunteered that a geranium ought to be taken away as it "had no pictures" (flowers).

During September he steadily improved, having regained the power to read to some extent with difficulty; could spell out meaning of advertisements on hoardings, but books soon tired him too much to continue ; could name his clildren, but always said "he" for " she," though unaware of this habitual error; memory for articles and pictures was perfect, and by September 3oth he wrote spontaneously one of several letter's (Fig. 2).

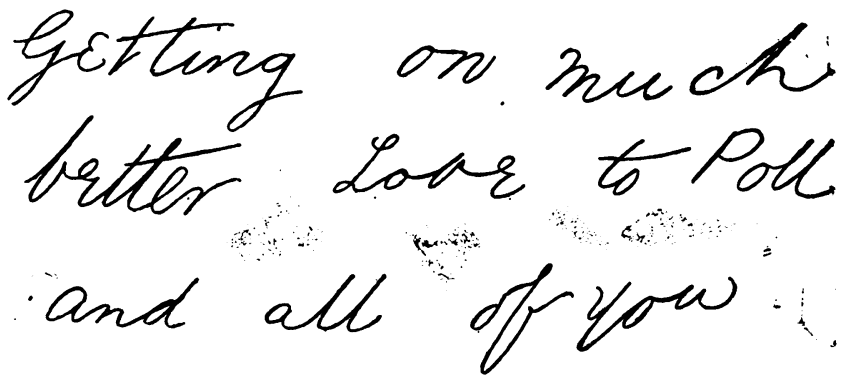

Fig. 2. 